\title{
S-Beta Thalassemia
}

National Cancer Institute

\section{Source}

National Cancer Institute. S-Beta Thalassemia. NCI Thesaurus. Code C81288.

A disorder characterized by the body's inability to synthesize beta-globin chains, leading to the formation of abnormal hemoglobin and anemia. This inherited autosomal recessive blood disorder is caused by germline mutation of the HBB gene. 